\title{
Effects of intraventricular injections of imipramine and 5-hydroxytryptamine on tonic immobility in chickens
}

\author{
CRAIG T. HARSTON and DAVID H. SIBLEY \\ Tulane University, New Orleans, Louisiana 70118 \\ and \\ GORDON G. GALLUP, JR. and LARRY B. WALLNAU \\ State University of New York at Albany, Albany, New York 12222
}

\begin{abstract}
While previous work has shown that peripherally administered serotonin and imipramine attenuate tonic immobility in chickens, in the present study intraventricular application of these compounds served to prolong the reaction. The data were discussed in terms of an inverse relationship between raphe electrical activity and the duration of tonic immobility in chickens.
\end{abstract}

Tonic immobility is found in a wide variety of animals and is sensitive to manipulations thought to effect fear. Under natural conditions, tonic immobility appears to function as the terminal reaction in a sequence of distant-dependent antipredator responses (Gallup, 1974; Ratner, 1967). Induced by a brief period of physical restraint, it is characterized by a peculiar catatonic-like state of motor inhibition which can last from a few minutes to several hours. Commonly observed responses during tonic immobility include Parkinsonian-like tremors, waxy flexibility, intermittent eye closure, and suppressed vocalization. Changes in heart and respiration rate, core temperature, and altered electroencephalographic patterns have also been reported (e.g., Carli, 1974; Klemm, 1971; Nash, Gallup, \& Czech, 1976).

Aghajanian and his co-workers (e.g., Aghajanian, Foote, \& Sheard, 1970; Aghajanian \& Haigler, 1973) have found changes in the electrical activity of raphe neurons following treatment with a variety of pharmacological agents which are thought to influence central serotonergic systems. Similar manipulations in chickens have revealed an apparent inverse relationship between the level of raphe electrical activity and the duration of tonic immobility (e.g., Maser, Gallup, \& Hicks, 1975). Serotonergic antagonists, such as d-LSD and BOL-148, inhibit raphe firing (Aghajanian, Foote, \& Sheard, 1970) but increase immobility (Maser et al., 1975). Tryptophan, the dietary precursor of serotonin, decreases raphe firing (Aghajanian, 1972) and potentiates the immobility reaction (Gallup, Wallnau, Boren, Gagliardi,

Requests for reprints should be sent to G. G. Gallup, Jr., Department of Psychology, State University of New York at Albany, Albany, New York 12222.
Maser, \& Edson, in press). Similarly, MAO inhibitors, such as pargyline and iproniazid, inhibit raphe activity (Aghajanian, Graham, \& Sheard, 1970), and prolong tonic immobility (Maser et al., 1975). Finally, the parallel is symmetrical, as illustrated by the fact that amphetamine increases the rate of raphe firing (Foote, Sheard, \& Aghajanian, 1969), while attenuating the immobility response (Boren \& Gallup; 1976).

That tonic immobility is a reflection of raphe electrical activity rather than brain serotonin per se is further suggested by the finding that PCPA depletes brain serotonin (Koe \& Weissman, 1966), but has no effect on either raphe firing (Aghajanian, Graham, \& Sheard, 1970), or tonic immobility (Hicks, Maser, Gallup, \& Edson, 1975; Maser et al., 1975). Likewise, 5-hydroxytryptophan, the immediate precursor of serotonin, has no effect on raphe activity (Aghajanian, Graham, \& Sheard, 1970) or immobility (Maser et al., 1975) when used in comparable doses.

Two apparent exceptions to the inverse relation between raphe firing and immobility duration have been reported. Peripheral injections of imipramine, which blocks serotonin uptake, inhibit raphe activity (Bramwell, 1972; Sheard, Zolovick, \& Aghajanian, 1972) and attenuate tonic immobility (Maser \& Gallup, 1974). Furthermore, microiontophoretic administration of serotonin suppresses raphe firing (Aghajanian \& Haigler, 1973), and intravenous injections of serotonin also suppress immobility (Maser et al., 1975). However, peripheral injections of serotonin increase raphe electrical activity (Mosko \& Jacobs, 1974); thus, when routes of administration are comparable, the inverse relation between raphe firing and duration of immobility appears to obtain. In an attempt to clarify the effect of centrally administered serotonin and to resolve the paradoxical 
results of imipramine, the present study investigated the effects of both of these compounds on tonic immobility following intraventricular administration.

\section{EXPERIMENT I}

\section{Method}

Fourteen straight-run Production Red chickens /Gallus gallus), obtained at one day of age from a local supplier and maintained on Purina Chick Chow, served as subjects. The birds were kept in a temperature-controlled room and provided with $14 \mathrm{~h}$ of artificial light per day.

When the chicks weighed about $300 \mathrm{~g}$, they were anesthetized with ether before and during cannula implantation. Each bird was placed in a stereotaxic instrument, with ear bars centered and the top of the skull adjusted to a flat position. A 21-ga guide cannula and 26-ga filler wire, which extended beyond the guide cannula tip $.5 \mathrm{~mm}$, were chronically implanted into the skull with three $4.75-\mathrm{mm}$ stainless steel screws and surrounded by cranioplastic cement. The tip of the guide cannula was located $6 \mathrm{~mm}$ ventral to dura, in the midline, and $1 / 3$ of the distance from the frontal-parietal suture to the occipital crest. Prior histological work showed that ink injected through a cannula at this location was found in the third and fourth ventricle. The wound was subsequently sutured closed, and the birds were allowed to recover for 4 days.

Eight birds were injected with imipramine and six birds with distilled water. Each injection was accomplished by removing the filler wire and inserting a 26-ga injector cannula through the guide cannula. Either $2 \mu \mathrm{l}$ of imipramine $\mathrm{HCl}(12.5 \mathrm{mg} / \mathrm{ml})$ or distilled water was injected into the brain, $6.5 \mathrm{~mm}$ ventral to the dura. A Hamilton microliter syringe was used to inject the solution over $15 \mathrm{sec}$, followed by another 15 -sec postinjection period prior to the removal of the injection cannula and replacement of the filler wire. Six birds injected with imipramine and three with water were tested for tonic immobility $30 \mathrm{~min}$ after injection, while the remaining chicks were tested $24 \mathrm{~h}$ later. To induce tonic immobility, each bird was held on its right side for $15 \mathrm{sec}$ and then gradually released. A timer was started at the end of the restraint period and stopped when the bird righted itself and got to its feet.

\section{Results}

Since the mean duration of immobility $30 \mathrm{~min}$ after injection of imipramine $(2,028.8 \mathrm{sec})$ was comparable to that obtained $24 \mathrm{~h}$ later $(2,570 \mathrm{sec})$, the data for both injection test intervals were pooled. A simple betweengroups analysis of variance showed that the differences between birds receiving imipramine, with an overall mean duration of immobility of $2,164.13 \mathrm{sec}$, was significantly different from the water controls, which had a mean of $650.66 \sec (F=5.38, \mathrm{df}=1 / 12, \mathrm{p}<.05)$. While birds became ataxic immediately after injection of imipramine, these motoric effects lasted only 10 to $15 \mathrm{~min}$.

\section{EXPERIMENT II}

\section{Method}

Ariother 14 straight-run Production Red chickens $(\bar{X}=400 \mathrm{~g})$ were anesthetized with Equithesan $(.3 \mathrm{cc} / 100 \mathrm{~g})$ and chronically implanted with cannulae, using the same procedure as in Experiment I. Ten birds were injected with serotonin $(2.0 \mu 1$ of $12.6 \mathrm{mg} / \mathrm{cc}$ ), and the remaining four birds received an intra- ventricular injection of an equal volume of distilled water. Birds in both groups were tested for tonic immobility $20 \mathrm{~min}$ after injection.

\section{Results}

Since the water controls from both experiments did not differ, these data were pooled for purposes of analysis. The mean duration of immobility for chicks receiving intraventricular injections of serotonin was $1,144.5 \mathrm{sec}$, as compared to 680.2 for pooled controls. Although in the predicted direction, an analysis of variance failed to reveal significant differences between groups $(\mathrm{F}=2.41, \mathrm{df}=1 / 18)$. While most birds receiving serotonin showed prolonged reactions, two showed discrepant response durations of less than $100 \mathrm{sec}$. A Fisher's exact probability test showed that, of the birds treated with serotonin, significantly more remained immobile for over $1,000 \mathrm{sec}$ ( 7 out of 10) than did the water-injected controls, where only 2 out of 10 exceeded $1,000 \sec (p=.032)$.

\section{DISCUSSION}

These findings bolster the possibility of an inverse relationship between raphe electrical activity and the duration of tonic immobility in chickens. The increase in immobility following intraventricular injections of serotonin parallels the finding that microiontophoretic application of serotonin serves to inhibit raphe firing (Aghajanian \& Haigler, 1973). The attenuation of immobility following intravenous administration of serotonin (Maser et al., 1975) is also consistent with the finding that peripheral injections of serotonin augment raphe firing (Mosko \& Jacobs, 1974).

Striking differences between central and peripheral administration of imipramine were also observed. Intramuscular injections of imipramine practically eradicate tonic immobility (Maser \& Gallup, 1974). However, when imipramine was applied intraventricularly, tonic immobility was potentiated rather than attenuated. This would appear consistent with the finding that imipramine inhibits raphe neurons (Bramwell, 1972; Sheard, Zolovick, \& Aghajanian, 1972), but additional work needs to be done on centrally administered imipramine and raphe firing.

These findings highlight the fact that route of administration can be a potent variable, and augment the growing evidence for an inverse and possibly functional relationship between raphe electrical activity and the duration of tonic immobility. Using transection techniques, Klemm (1971) has shown that tonic immobility is related to the integrity of as yet unidentified structures somewhere in the area of midbrain reticular formation. That many raphe nuclei are found in roughly the same general area of the brain provides further support for the possibility of a functional relationship between the activity of raphe neurons and the duration of tonic immobility.

\section{REFERENCES}

Aghajanian, G. K. Influence of drugs on the firing of serotonincontaining neurons in brain. Federation Proceedings, 1972, 31, $91-96$.

Aghajanian, G. K., Foote, W. E., \& Sheard, M. H. Action of psychotogenic drugs on single midbrain raphe neurons. Journal of Pharmacology and Experimental Therapeutics, 1970, 171, 178-187.

aghajanian, G. K., Graham, A. W., \& Sheard, M. H. Serotonin-containing neurons in brain: Depression of firing by monoamine oxidase inhibitors. Science, 1970, 169, 1100-1102. 
Aghajanian, G. K., \& Haigler, H. J. Direct and indirect actions of LSD, serotonin, and related compounds on serotonincontaining neurons. In J. Barchas \& E. Usdin (Eds.), Serotonin and behavior. New York: Academic Press, 1973.

Boren. J.. \& Gallup, G. G.. JR. Amphetamine attenuation of tonic immobility. Physiological Psychology, 1976, in press.

Bramwell, G. J. Effect of imipramine on unit activity in the midbrain raphe of rats. British Journal of Pharmacology, 1972. 44. 345-346.

CARLI. G. Blood pressure and heart rate in the rabbit during animal hypnosis. Electroencephalography and Clinical Neurophysiology. 1974, 37, 231-237.

Foote, W. E., Sheard, M. H., \& Aghajanian, G. K. Comparison of effects of LSD and amphetamine on midbrain raphe units. Nature, 1969, 222, 567-569.

GalluP, G. G., JR. Animal hypnosis: Factual status of a fictional concept. Psychological Bulletin, 1974, 81, 836-853.

Gallup, G. G., JR., Wallnau, L. B., Boren, J. L., Gagliardi, G. J., Maser, J. D., \& Edson, P. H. Tryptophan and tonic immobility in chickens: Effects of dietary and systemic manipulations. Journal of Comparative and Physiological Psychology, in press.

Hicks, L. E., Maser, J. D., Gallup, G. G., JR., \& Edson, P. H. Possible serotonergic mediation of tonic immobility: Effects of morphine and serotonin blockade. Psychopharmacologia, 1975, 42, 51-56.

KLEMM, W. R. Neurophysiologic studies of the immobility reflex (“animal hypnosis"). In S. Ehrenpreis \& O. C. Solnitzky (Eds.). Neuroscience research (Vol. 4). New York: Academic Press. 1971.

Koe, B. K., \& Weissman, A. p-Chlorophenylalanine: A specific depleter of brain serotonin. Journal of Pharmacology and Experimental Therapeutics, 1966, 154, 499-516.

MASER, J. D., \& GalluP, G. G., JR. Tonic immobility in chickens: Catalepsy potentiation by uncontrollable shock and alleviation by imipramine. Psychosomatic Medicine, 1974, 36, 199-205.

Maser, J. D., GalluP, G. G., JR., \& Hicks, L. E. Tonic immobility in chickens: Possible involvement of monoamines. Journal of Comparative and Physiological Psychology, 1975, 89, 319-328.

Mosкo, S., \& JACoBs, B. L. Effect of peripherally administered serotonin on the neuronal activity of midbrain raphe neurons. Brain Research, 1974, 79, 315-320.

Nash, R. F., Gallup, G. G., JR., \& Czech, D. A. Psychophysical correlates of tonic immubility in the domestic chicken (Gallus gallus). Physiology and Behavior, 1976, in press.

RATNER, S. C. Comparative aspects of hypnosis. In J. E. Gordon (Ed.), Handbook of clinical and experimental hypnosis. New York: Macmillan, 1967.

Sheard, M. H., Zolovick, A., \& Aghajanian, G. K. Raphe neurons: Effect of tricyclic antidepressant drugs. Brain Research, 1972, 43, 690-694.

(Received for publication July 16, 1976.) 